\title{
The Comprehensive Assessment of Dam Risk Consequences Caused by The Dam Failure Based on The Set Pair Analysis
}

\author{
Zongkun $\mathrm{Li}^{\mathrm{a}}$, Qi Li \\ School of Zhengzhou, Zhengzhou University, Zhengzhou 450001, China. \\ aLzongkun@zzu.edu.cn, biqzzu@163.com
}

Keywords: dam risk consequences, comprehensive evaluation, set pair analysis, set pair potential, sorting

\begin{abstract}
The comprehensive assessment of dam risk consequences caused by the dam failure is difficult because of the uncertainty, inter related and the non unification of the risk consequences. For this problem, combining with the existing laws and regulations of dam failure accidents classification rules, this paper propose an dam risk comprehensive evaluation modelmodel based on set pair analysis. This modle can discribe the degree of convergence of the consequences and the accident risk level from the same, different, opposite three aspects. According to the Maximum set pair potential theory, the model can get the dam risk consequences comprehensive evaluation level and the sorting. The evaluation model was applied to 5 dams comprehensive evaluation of jiangxi province. The evaluation result was compared with another resulet based on the attribute interval computation model. Results show that the set pair analysis evaluation model process is simple, and has less computation, and the evaluation result is reasonable, objective and comprehensive, clear. This model provides a new way for comprehensive evaluation for dam risk consequences.
\end{abstract}

\section{Introduction}

According to the definition of ICOLD Beijing meeting in 2000 [1] :Risk is the product of dam failure probability and consequences of the risk, namely R (risk) $=\mathrm{P}$ (probability) $\mathrm{x}$ L (consequences). At present, in view of the research is relatively substantial risk probability, and the studies of risk consequences are relatively scarce. With the increase of population and economy, social level unceasing enhancement, the consequences of the dam crash will be more serious than ever, society will be more difficult to bear [2-3]. Therefore, carries on the comprehensive evaluation of dam risk consequence can not only improve the dam risk management theory, but also can determine the level of the accident, according to the results of the evaluation of scientific risk management approach is of great significance.

Risk consequences including loss of life, economic losses and social impact, environmental impact assessment index. At present, the scholars at home and abroad in view of the above each single index, especially on the research of the loss of life and economic loss, has made certain research results [4-7]. Because there are a lot of uncertainties between the 4 evaluation indexes, and the evaluation results of each index have different dimensions, the research on the comprehensive evaluation model of the risk consequence is still few. Paper [8] use linear weighted sum method constructing dam comprehensive evaluation function of $\mathrm{L}$, and establish the dam failure consequences severity evaluation model. Paper [9-10] establish the comprehensive evaluation model of dam risk consequences based on the grey correlation method and principal component analysis; Paper [11] established a comprehensive evaluation of dam failure consequences of attribute interval recognition model based on the basis of attribute interval recognition theory. The above methods are each have advantages and disadvantages.

\section{The theory of set pair analysis}

The core theory of set pair analysis [12] is to describe the system's certainty by "the same" and "opposition", using the "difference" to describe the uncertainty of the system. In view of the problems 
for study, to build a connection of two sets of $Q$ and $P$ sets of $H=(Q, P)$, and through the connection degree $\mu$ on characteristics of two sets in the set from the sameness, difference and opposition 3 quantitative characterization, connection degree of the Mu expressions such as formula (1):

$$
\mu=\frac{S}{N}+\frac{F}{N} i+\frac{P}{N} j=a+b i+c j
$$

In the formula: $\boldsymbol{\mu}$ refer to the same and different connection degree; $a, b, c$ refer to the set $\mathrm{Q}$ and P with once, difference and opposition between degrees, $a, b, c \in[0,1]$, and $a, b, c$ satisfy the normalization condition of $a+b+c=1$; N refer to the total number of features, $S, K$ refer to the two sets the number of common features and the number of opposite characteristics, $F=N-S-K$; $i$ for the difference degree coefficient, in $[1,1]$ interval values according to different situation; $j$ for the coefficients of opposites, value of 1.

\section{Comprehensive evaluation of dam risk consequences set pair analysis model}

Based on set pair analysis of dam risk consequences comprehensive evaluation is the index evaluation and risk rating standard set a set of $\mathrm{H}$, by calculating the sameness, difference and inverse coefficient to determine a consequence of dam risk degree of connection matrix $\boldsymbol{\mu}$; Secondly, according to the weight coefficient of each index, determine the comprehensive contact degree matrix $A$; Finally, to determine the set of potential vector $N_{0}$ and according to the maximum set of potential theory to determine the level of comprehensive evaluation of dam risk consequences, namely consequence of dam risk assessment for set of vector potential in the maximal set of the corresponding potential level and specific calculation steps are as follows:

(1) Set pair model construction

Set $Q=\left\{q_{1}, q_{2}, q_{3}, q_{4}\right\}$ and set $P$ respectively evaluation value and evaluation standard collection, according to set pair analysis theory, set up two sets of set pair H（Q,P）, including:

$$
P=\left[\begin{array}{cccc}
X_{10} & X_{11} & \cdots & X_{1 j} \\
X_{20} & X_{21} & \cdots & X_{2 j} \\
\vdots & \vdots & & \vdots \\
X_{k 0} & X_{k 1} & \cdots & X_{k j}
\end{array}\right]
$$

In the formula: $\mathrm{q}_{k}$ refer to the evaluation index value $(\mathrm{k}=1,2,3,4) ; X_{k j}$ refer to the first $k$ evaluation index corresponds to the critical value $(k, j=1,2,3,4)$ of the first $\mathrm{j}$ evaluation criteria, the specific critical values of each evaluation criteria are shown in table 1.

Table 1 Comprehensive evaluation standard of dam risk consequences

\begin{tabular}{ccccc}
\hline Index & $\begin{array}{c}\text { The general } \\
\text { accident }\end{array}$ & $\begin{array}{c}\text { Larger } \\
\text { accident }\end{array}$ & $\begin{array}{c}\text { Major } \\
\text { accident }\end{array}$ & $\begin{array}{c}\text { Extremely } \\
\text { large } \\
\text { accidents }\end{array}$ \\
\hline $\begin{array}{c}\text { Loss of life/people } \\
\text { Economic losses / } \\
\text { Million }\end{array}$ & $1 \sim 3$ & $3 \sim 10$ & $10 \sim 30$ & $30 \sim 100000$ \\
Social impact factor & $1 \sim 3$ & $1000 \sim 5000$ & $5000 \sim 10000$ & $\begin{array}{c}10000 \sim 10000 \\
00\end{array}$ \\
Environmental impact & $1 \sim 3$ & $3 \sim 12$ & $8 \sim 25$ & $25 \sim 100$ \\
factor & $12 \sim 3 \sim 0$ & $40 \sim 100$ \\
\hline
\end{tabular}

(2) The determination of connection degree

According to the theory of set pair analysis, the connection degree of 4 accidents $\mu_{1}, \mu_{2}, \mu_{3}, \mu_{4}$ can be determined, and the calculation method is as shown in formula (3) - formula (6): 


$$
\begin{aligned}
& \mu_{1}=\left\{\begin{array}{l}
1, q \in\left[X_{0}, X_{1}\right) \\
\frac{X_{1}}{q}+\frac{q-X_{1}}{q} i, q \in\left[X_{1}, X_{2}\right) \\
\frac{X_{1}}{q}+\frac{X_{2}-X_{1}}{q} i+\frac{q-X_{2}}{q} j, q \in\left[X_{2}, X_{4}\right)
\end{array}\right. \\
& \mu_{2}=\left\{\begin{array}{l}
\frac{X_{2}-X_{1}}{X_{2}-q}+\frac{X_{1}-q}{X_{2}-q} i, q \in\left[X_{0}, X_{1}\right) \\
1, q \in\left[X_{1}, X_{2}\right) \\
\frac{X_{2}-X_{1}}{q-X_{1}}+\frac{q-X_{2}}{q-X_{1}} i, q \in\left[X_{2}, X_{3}\right) \\
\frac{X_{2}-X_{1}}{q-X_{1}}+\frac{X_{3}-X_{2}}{q-X_{1}} i+\frac{q-X_{3}}{q-X_{1}} j, q \in\left[X_{3}, X_{4}\right)
\end{array}\right. \\
& \left(\frac{X_{3}-X_{2}}{X_{3}-q}+\frac{X_{2}-X_{1}}{X_{3}-q} i+\frac{X_{1}-q}{X_{3}-q} j, q \in\left[X_{0}, X_{1}\right)\right. \\
& \mu_{3}=\left\{\begin{array}{l}
\frac{X_{3}-X_{2}}{X_{3}-q}+\frac{X_{2}-q}{X_{3}-q} i, q \in\left[X_{1}, X_{2}\right) \\
1, q \in\left[X_{2}, X_{3}\right) \\
\frac{X_{3}-X_{2}}{q-X_{2}}+\frac{q-X_{3}}{q-X_{2}} i, q \in\left[X_{3}, X_{4}\right)
\end{array}\right. \\
& \left(\frac{X_{4}-X_{3}}{X_{4}-q}+\frac{X_{3}-X_{2}}{X_{4}-q} i+\frac{X_{2}-q}{X_{4}-q} j, q \in\left[X_{0}, X_{2}\right)\right. \\
& \mu_{4}=\left\{\begin{array}{l}
\frac{X_{4}-X_{3}}{X_{4}-q}+\frac{X_{3}-q}{X_{4}-q} i, q \in\left[X_{2}, X_{3}\right) \\
1, q \in\left[X_{3}, X_{4}\right)
\end{array}\right.
\end{aligned}
$$

In the formula: $X_{0} \sim X_{4}$ is the critical value of the evaluation criteria, and the critical values of different evaluation criteria are different. Such as loss of life, the critical values of the assessment criteria are $\mathrm{X}_{0}=1, \mathrm{X}_{1}=3, \mathrm{X}_{2}=10, \mathrm{X}_{3}=30, \mathrm{X}_{4}=100000$.

(3) The determination of evaluation grades

First of all, by the step (2) the connection degree of the calculation results, a link can be set for the dam risk consequence degree matrix $\boldsymbol{\mu}=(a+b i+c j)_{j \times k}$, and according to the evaluation index weight vector $W=\left[\begin{array}{lll}\omega_{1}, & \omega_{2}, \ldots, \omega_{k}\end{array}\right]$, dam and risk consequence evaluation comprehensive contact degree matrix $\boldsymbol{A}=\boldsymbol{W} \cdot \boldsymbol{\mu}$; Secondly, according to the integrated connection degree matrix for dam risk consequences set pair potential vector N0, and according to the maximum set of potential theory to determine the consequence of dam risk evaluation grade set.

\section{Apply and Result}

This paper, taking jiangxi province xialan, shibitan, changlong, longshan, lingtan 5 dam for example, using the set pair analysis model for comprehensive evaluation of each dam risk consequences. 5 reservoirs dam in all kinds of evaluation indexes as shown in table 2. 
Table 25 reservoirs dam risk consequences index data

\begin{tabular}{cccccc}
\hline Name of the reservoir & $\begin{array}{c}\text { Xiala } \\
\mathrm{n}\end{array}$ & $\begin{array}{c}\text { Shibiken } \\
\mathrm{g}\end{array}$ & $\begin{array}{c}\text { Changlo } \\
\mathrm{ng}\end{array}$ & $\begin{array}{c}\text { Longsh } \\
\text { an }\end{array}$ & $\begin{array}{c}\text { Lingta } \\
\mathrm{n}\end{array}$ \\
\hline Loss of life/people & 735 & 975 & 454 & 887 & 1709 \\
Economic losses / Million & 25 & 41 & 35 & 25 & 20 \\
Social impact factor & 1.43 & 1.43 & 1.43 & 1.43 & 1.43 \\
$\begin{array}{c}\text { Environmental impact } \\
\text { factor }\end{array}$ & 13.82 & 9.68 & 19.28 & 34.85 & 7.71 \\
\hline
\end{tabular}

By formula (3) - (6) to calculate the reservoir dam risk consequences $\boldsymbol{\mu}$ connection degree matrix, the calculation results are as follows:

$$
\begin{aligned}
& \boldsymbol{\mu}_{\text {xia }}=\left[\begin{array}{cccc}
\mu_{1} & \mu_{2} & \mu_{3} & \mu_{4} \\
0.0041+0.0095 i+0.9864 j & 0.0096+0.0273 i+0.9631 j & 0.0276+0.9724 i+0 j & 1+0 i+0 j \\
0.0040+0.0160 i+0.9800 j & 0.0161+0.0201 i+0.9638 j & 0.0204+0.9796 i+0 j & 1+0 i+0 j \\
1+0 i+0 j & 0.7610+0.2930 i+0 j & 0.7213+0.2121 i+0.0666 j & 0.7609+0.1725 i+0.0666 j \\
0.2171+0.6512 i+0.1317 j & 0.8318+0.1682 i+0 j & 1+0 i+0 j & 0.6962+0.3038 i+0 j
\end{array}\right] \\
& \boldsymbol{\mu}_{\mathrm{shi}}=\left[\begin{array}{cccc}
\mu_{1} & \mu_{2} & \mu_{3} & \mu_{4} \\
0.0031+0.0072 i+0.9897 j & 0.0072+0.0206 i+0.9631 j & 0.0207+0.9793 i+0 j & 1+0 i+0 j \\
0.0024+0.0098 i+0.9878 j & 0.0098+0.0122 i+0.9780 j & 0.0123+0.9877 i+0 j & 1+0 i+0 j \\
1+0 i+0 j & 0.7610+0.2930 i+0 j & 0.7213+0.2121 i+0.0666 j & 0.7609+0.1725 i+0.0666 j \\
0.3099+0.6901 i+0 j & 1+0 i+0 j & 0.9235+0.0765 i+0 j & 0.6643+0.3100 i+0.0257 j
\end{array}\right] \\
& \boldsymbol{\mu}_{\text {chang }}=\left[\begin{array}{cccc}
\mu_{1} & \mu_{2} & \mu_{3} & \mu_{4} \\
0.0066+0.0154 i+0.9780 j & 0.0155+0.0443 i+0.9402 j & 0.0450+0.9550 i+0 j & 1+0 i+0 j \\
0.0029+0.0114 i+0.9857 j & 0.0115+0.0143 i+0.9742 j & 0.0145+0.9855 i+0 j & 1+0 i+0 j \\
1+0 i+0 j & 0.7610+0.2930 i+0 j & 0.7213+0.2121 i+0.0666 j & 0.7609+0.1725 i+0.0666 j \\
0.1556+0.4668 i+0.3776 j & 0.5528+0.4472 i+0 j & 1+0 i+0 j & 0.7433+0.2567 i+0 j
\end{array}\right] \\
& \boldsymbol{\mu}_{\text {long }}=\left[\begin{array}{cccc}
\mu_{1} & \mu_{2} & \mu_{3} & \mu_{4} \\
0.0034+0.0079 i+0.9887 j & 0.0080+0.0229 i+0.9691 j & 0.0231+0.9769 i+0 j & 1+0 i+0 j \\
0.0040+0.0162 i+0.9800 j & 0.0161+0.0201 i+0.9638 j & 0.0204+0.9796 i+0 j & 1+0 i+0 j \\
1+0 i+0 j & 0.7610+0.2930 i+0 j & 0.7213+0.2121 i+0.0666 j & 0.7609+0.1725 i+0.0666 j \\
0.0861+0.2582 i+0.6557 j & 0.2826+0.7174 i+0 j & 1+0 i+0 j & 0.9210+0.0790 i+0 j
\end{array}\right] \\
& \boldsymbol{\mu}_{\text {ling }}=\left[\begin{array}{cccc}
\mu_{1} & \mu_{2} & \mu_{3} & \mu_{4} \\
0.0018+0.0041 i+0.9941 j & 0.0041+0.0117 i+0.9842 j & 0.0118+0.9882 i+0 j & 1+0 i+0 j \\
0.0050+0.0200 i+0.9750 j & 0.0201+0.0251 i+0.9548 j & 0.0256+0.9744 i+0 j & 1+0 i+0 j \\
1+0 i+0 j & 0.7610+0.2930 i+0 j & 0.7213+0.2121 i+0.0666 j & 0.7609+0.1725 i+0.0666 j \\
0.3891+0.6109 i+0 j & 1+0 i+0 j & 0.8671+0.1329 i+0 j & 0.6501+0.3034 i+0.0465 j
\end{array}\right]
\end{aligned}
$$

Using analytic hierarchy process (AHP) to determine evaluation index weights. Based on paper [13], loss of life, economic loss, environmental impact, the importance of social impact ratio was 7.0:1.0:1.5:1.5, so the weight vector $W=[0.636,0.091,0.136,0.136]$, available dam risk comprehensive contact degree matrix, the calculation results are as follows:

$$
\begin{aligned}
& \mathrm{XL}: A_{\text {xia }}=W \cdot \boldsymbol{\mu}_{\text {xia }}=\left[\begin{array}{l}
0.1685+0.0961 i+0.7344 j \\
0.2242+0.0746 i+0.7002 j \\
0.2535+0.7364 i+0.0091 j \\
0.9252+0.0648 i+0.0090 j
\end{array}\right] \mathrm{SBK}: A_{\text {shi }}=W \cdot \boldsymbol{\mu}_{\text {shi }}=\left[\begin{array}{l}
0.1803+0.0993 i+0.7194 j \\
0.1450+0.0467 i+0.7073 j \\
0.2380+0.7519 i+0.0091 j \\
0.9208+0.0656 i+0.0126 j
\end{array}\right] \\
& \mathrm{CL}: A_{\text {chang }}=W \cdot \boldsymbol{\mu}_{\mathrm{C}}=\left[\begin{array}{l}
0.1616+0.0743 i+0.7631 j \\
0.1896+0.1228 i+0.6866 j \\
0.2460+0.7259 i+0.0091 j \\
0.9316+0.0584 i+0.0090 j
\end{array}\right] \mathrm{LS}: A_{\text {long }}=W \cdot \boldsymbol{\mu}_{\mathrm{L}}=\left[\begin{array}{l}
0.1502+0.0416 i+0.8072 j \\
0.1485+0.1464 i+0.7041 j \\
0.2506+0.7393 i+0.0091 j \\
0.9557+0.0342 i+0.0091 j
\end{array}\right] \\
& \mathrm{LT}: A_{\text {ling }}=W \cdot \boldsymbol{\mu}_{\text {ling }}=\left[\begin{array}{l}
0.1905+0.0875 i+0.7210 j \\
0.2439+0.0423 i+0.7128 j \\
0.2259+0.7641 i+0.0090 j \\
0.9220+0.0647 i+0.0123 j
\end{array}\right]
\end{aligned}
$$


Determine the set pair potential vector. The calculation results as shown in table 3:

Table 3 Set pair potential vector calculation results table

\begin{tabular}{ccc}
\hline $\begin{array}{c}\text { Name of the } \\
\text { reservoir }\end{array}$ & The set pair potential vector & Maximum set pair potential \\
\hline Xialan & {$[0.2294,0.3202,27.9883,102.1425]$} & 102.1425 \\
Shibikeng & {$[0.2507,0.3463,26.2738,73.3563]$} & 73.3563 \\
Changlong & {$[0.2118,0.2761,29.1508,102.8497]$} & 102.8497 \\
Longshan & {$[0.1861,0.2109,27.6723,105.5178]$} & 105.5178 \\
Lingtan & {$[0.2643,0.3422,24.9356,75.2452]$} & 59.7400 \\
\hline
\end{tabular}

According to the maximum set of potential theory, combined with table 3, shows 5 reservoir dam break consequence synthetical evaluation are especially serious accident and according to set the maximum potential size to the severity of the dam failure consequences from big to small order are: Longshan, Changlong, Xialan, Shi bikeng, Lingtan.

\section{Summary}

Dam risk assessment is the foundation and key of dam risk analysis and risk management. Set pair analysis as a method for dealing with uncertainty system theory is applied to the comprehensive evaluation of dam risk consequence. In view of the uncertainty of the risk consequences, this study established the comprehensive evaluation of dam risk consequences set pair analysis model, and the model was applied to jiangxi province 5 reservoirs dam risk evaluation, the evaluation results and risk consequences severity sorting and evaluation results of calculation model based on attribute interval completely consistent and more comprehensive. At the same time, the model has the characteristics of simple logical thinking, less computation and easy implementation. It provides a new method for the comprehensive evaluation of dam risk.

\section{Reference}

[1]. JIANG Shuhai, FAN Ziwu. Study of tolerable risk analysis for dam safety[J]. HYDRO-SCIENCE AND ENGINEERING, 2003, (3): 7-12.

[2]. LI Zongkun, GE Wei, WANG Juan, et al. Strategic consideration of dam safety management and risk management in China[J]. ADVANCES IN WATER SCIENCE, 2015, 26(4): 589-595.

[3]. LI Lei, CAI Yuebo, SHENG Jinbao. Dam safety and risk management in China and its strategic consideration [J]. Chinese Journal of Geotechnical Engineering, 2008, 30(11):1581-1587.

[4]. Assaf H, Hartford D N D, Cattanach J D. Estimating Dam Breach Flood Survival Probabilities [J]. ANDOLD Bulletin, No 107: 2-42.

[5]. McClelland M, Bowles D S. Towards Improved Life Loss Estimation Methods: Lessons From Case Histories [R]. Seinajoki: Rescdam Seminar, 2000.

[6]. FAN Ziwu, JANG Shuhai. Application of tolerance risk analysis method in decision-making of flood prevention [J]. SHUI LI XUEBAO, 2005, 36(5): 618-623.

[7]. HE Xiaoyan, SUN Dandan, HUANG Jinchi. Assessment on social and environment impacts of dam break [J]. Chinese Journal of Geotechnical Engineering, 2008, 30(11):1752-1757.

[8]. LI Lei, WANG Renzhong, SHENG Jinbao. Study on evaluation models of severity degree of dam failure impact[J]. Journal of Safety and Environment, 2006, 6(1):1-4.

[9]. SUN Weiwei, LI Lei. Comprehensive Model for Assessing Hazard Consequences Caused by Dam Failure Based on Principal Component Analysis[J]. Journal of Yangtze River Scientific Research Institute, 2010, 27(12):22-26. 
[10].SUN Weiwei, LI Lei. Comprehensive hazard assessment model for consequences caused by dam failure based on fuzzy mathematics method[J]. Hydro-Science and Engineering, 2010, (4):16-20.

[11]. ZOU Qiang, ZHOU Jianzhong, YANG Xiaoling, et al. A Comprehensive Assessment model for severity degree of dam failure impact based on attribute interval recognition theory[J]. Journal of Sichuan University（Engineering science edition ）, 2011, 43(2):45-50.

[12]. ZHAO Keqin. Set pair analysis and its preliminary application[M]. Hangzhou: Zhejiang scienc e and technology Press, 2000.

[13]. LI Lei, WANG Renzhong, SHENG Jinbao, et al. Dam risk evaluation and risk management[M]. Beijing: China Water\&Power Press, 2006. 